\title{
Corrigendum
}

\section{Corrigendum to "Epidemiological Trends of Head and Neck Cancer: A Population-Based Study"}

\author{
Kangwen Guo, ${ }^{1}$ Weiliang Xiao, ${ }^{2}$ Xinggui Chen, ${ }^{3}$ Zhenying Zhao, ${ }^{4}$ Yuanxiong Lin, ${ }^{1}$ \\ and Ge Chen ${ }^{1}$ \\ ${ }^{1}$ Department of Radiotherapy, Central Hospital of Guangdong Nongken, Zhanjiang, China \\ ${ }^{2}$ Department of Intervention, The First Affiliated Hospital of Guangzhou University of Chinese Medicine, Guangzhou, China \\ ${ }^{3}$ Cancer Center, Affiliated Hospital of Guangdong Medical University, Zhanjiang, China \\ ${ }^{4}$ Department of Pharmacy, Tianjin Union Medical Center, Tianjin, China
}

Correspondence should be addressed to Kangwen Guo; guokangwen90@163.com

Received 2 November 2021; Accepted 2 November 2021; Published 24 November 2021

Copyright (C) 2021 Kangwen Guo et al. This is an open access article distributed under the Creative Commons Attribution License, which permits unrestricted use, distribution, and reproduction in any medium, provided the original work is properly cited.

In the article titled "Epidemiological Trends of Head and Neck Cancer: A Population-Based Study" [1], the affiliation order is incorrect.

The corrected affiliation is shown in the author information above.

\section{References}

[1] K. Guo, W. Xiao, X. Chen, Z. Zhao, Y. Lin, and G. Chen, "Epidemiological trends of head and neck cancer: a populationbased study," BioMed Research International, vol. 2021, Article ID 1738932, 14 pages, 2021. 